\title{
Seasonal Variation in the Effects of Adrenalin and Glucagon in Rana pipiens ${ }^{1}$
}

\author{
Eugenia S. Farrar and B. E. Frye \\ Department of Zoology, Iowa State University, Ames, Iowa; and \\ Department of Zoology, University of Michigan, Ann Arbor, Michigan
}

Accepted April 22, 1977

\begin{abstract}
The effects of adrenalin and glucagon on blood glucose and lactate were compared in winter, summer, and fall Rana pipiens. Hyperglycemic responses to glucagon (1 $\mathrm{mg} / \mathrm{kg}$ ) were slightly lower in winter than in summer and fall frogs. Hyperglycemic and lactacidemic responses to adrenalin $(1 \mathrm{mg} / \mathrm{kg})$ were considerably greater in fall than in summer and winter frogs.
\end{abstract}

It is abundantly clear that the carbohydrate reserves of anuran amphibians vary with the season (Byrne and White, 1975; Farrar, 1972; Hermansen and Jörgensen, 1969; Mizell, 1965; Smith, 1954). Liver and muscle glycogen levels are higher in late fall and winter than in late spring and summer, while blood sugar levels are generally higher in summer than in winter. In several species, the highest annual blood glucose levels occur during the breeding period (Byrne and White, 1975; Hermansen and Jörgensen, 1969; Smith, 1954) and an additional peak may occur in late summer or early fall when glycogen is being stored (Hanke and Neumann, 1972).

It follows that hormones involved in the regulation of carbohydrate metabolism should be expected to exhibit seasonally variable effects. Insulin favors glycogen synthesis from pyruvate in frog muscle isolated from winter $R$. pipiens but favors pyruvate oxidation in summer frog muscle (Gourley et al., 1969). Rana temporaria often die after insulin $(4 \mathrm{IU} / \mathrm{kg})$ in summer but may show a lack of response for a few hours following the same dose in winter (Hanke and Neumann, 1972). ACTH, aldosterone, and corticosterone elevate blood

\footnotetext{
${ }^{1}$ Supported by NIH Predoctoral Fellowship No. 5-F1-GM-33, 848-02.
}

glucose levels in Rana temporaria throughout the year except during spawning (February and March) and September, times when blood glucose levels are normally high (Hanke and Neumann, 1972). Glucagon lowers Rana temporaria liver glycogen in July when glycogen levels are low but is variably effective at other times of the year (Hanke and Neumann, 1972). Smith (1954) suggested that the hyperglycemic response to excitement seen in $R$. temporaria only in spawning and in summer might be due to variations in the circulating levels of adrenergic compounds. Adrenalin caused hyperglycemia in both summer and winter $R$. temporaria acclimated at $5^{\circ}$ but not in those frogs acclimated at $25^{\circ}$. The higher temperature alone caused loss of liver glycogen and the hormone response was not apparent (Harri and Lindgren, 1972).

Because adrenalin and glucagon have potentially similar liver glycogenolytic activities in mammals (see reviews by Ellis, 1956, and Foá, 1968) and have potentially seasonally variable effects in frogs, their effects on blood glucose and lactate were compared in Rana pipiens during several seasons.

\section{METHODS}

Male Rana pipiens from North Dakota weighing 30 to $80 \mathrm{~g}$ were provided by the Nasco Supply Company. 
During winter the frogs were kept in artesian wells in hibernating condition prior to shipment; freshly collected specimens were provided during summer and fall. $\Lambda$ fter receipt the frogs were maintained in tanks with running tap water at a temperature of 15 to $17^{\circ}$ and on a 12-hr light: $12 \mathrm{hr}$ dark photoperiod. Animals were force-fed 1 to $2 \mathrm{~g}$ of liver twice a week and were fasted for 3 to 5 days prior to use. All animals were kept in the lab for 2 weeks prior to use.

Frogs were injected intraperitoneally with saline, adrenalin ( $1 \mathrm{mg} / \mathrm{kg}$, as the hydrochloride; ParkeDavis), or glucagon (1 $\mathrm{mg} / \mathrm{kg}$, Eli Lilly Co.) and placed in moist, aerated containers at room temperature until sampling time. Sampling intervals were 0,1 , $3,5,10$, and 24 hr postinjection. Individuals were then anesthetized, and $150 \mu$ of blood was removed from the heart. Animals were anesthetized by immersion in $0.5 \%$ Tricaine methane sulfonate (Finquel, Ayerst Laboratories). Because repeated anesthetization causes hyperglycemia in Rana pipiens (Farrar, 1972), animals were sampled only once in each experiment. Blood samples $(50 \mu l)$ were analyzed for glucose, using glucose oxidase (Glucostat, Worthington Biochem. Corp.), and for lactate, using the lactate dehydrogenase method of Scholz et al. (1959). Experiments were performed during fall (September), winter (November to early March), and summer (August).

\section{RESULTS}

Responses to both hormones were seasonal, but differences in the seasonal response to the two hormones were observed. Glucagon was significantly less effective in winter than in summer or fall (Fig. 1). A 1-mg/kg dose caused less hyperglycemia, and the response was delayed by at least $1 \mathrm{hr}$ in winter. When the dose was doubled the summer or fall response could be reproduced in winter frogs (Farrar, 1972). In contrast, adrenalin responses were not lowered in winter (Fig. 2); winter and summer frogs both responded with hyperglycemic curves very similar in pattern to that seen after glucagon treatment in summer.

Strikingly increased adrenalin responses were seen in fall frogs. Both hyperglycemia

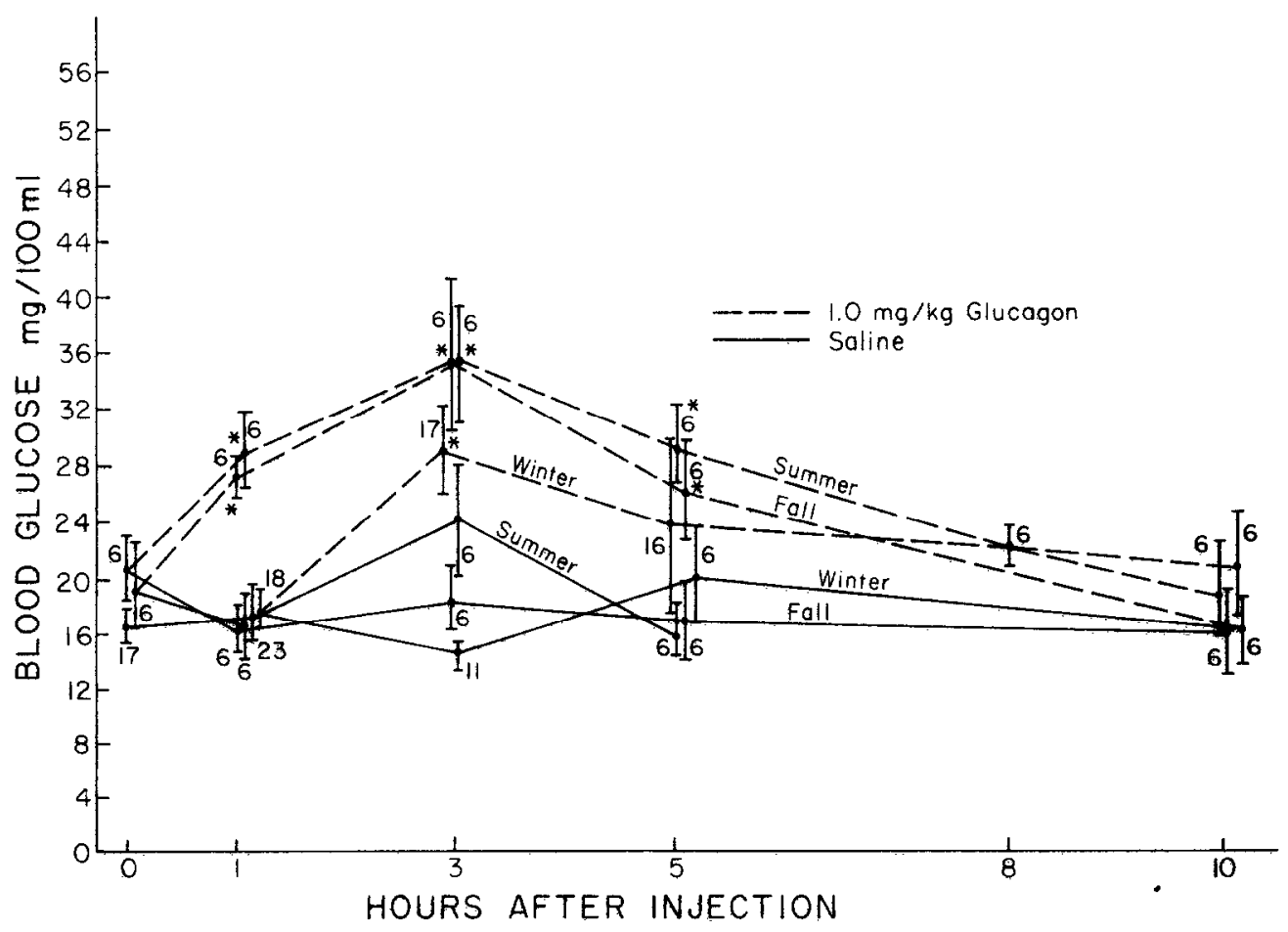

Fig. 1. Effects of glucagon on Rana pipiens blood glucose in summer, fall, and winter (Means \pm standard errors). Numbers of animals in each group are indicated beside each point on the curves. Asterisks indicate significant $(p \leqslant .05)$ difference from the respective seasonal control. 


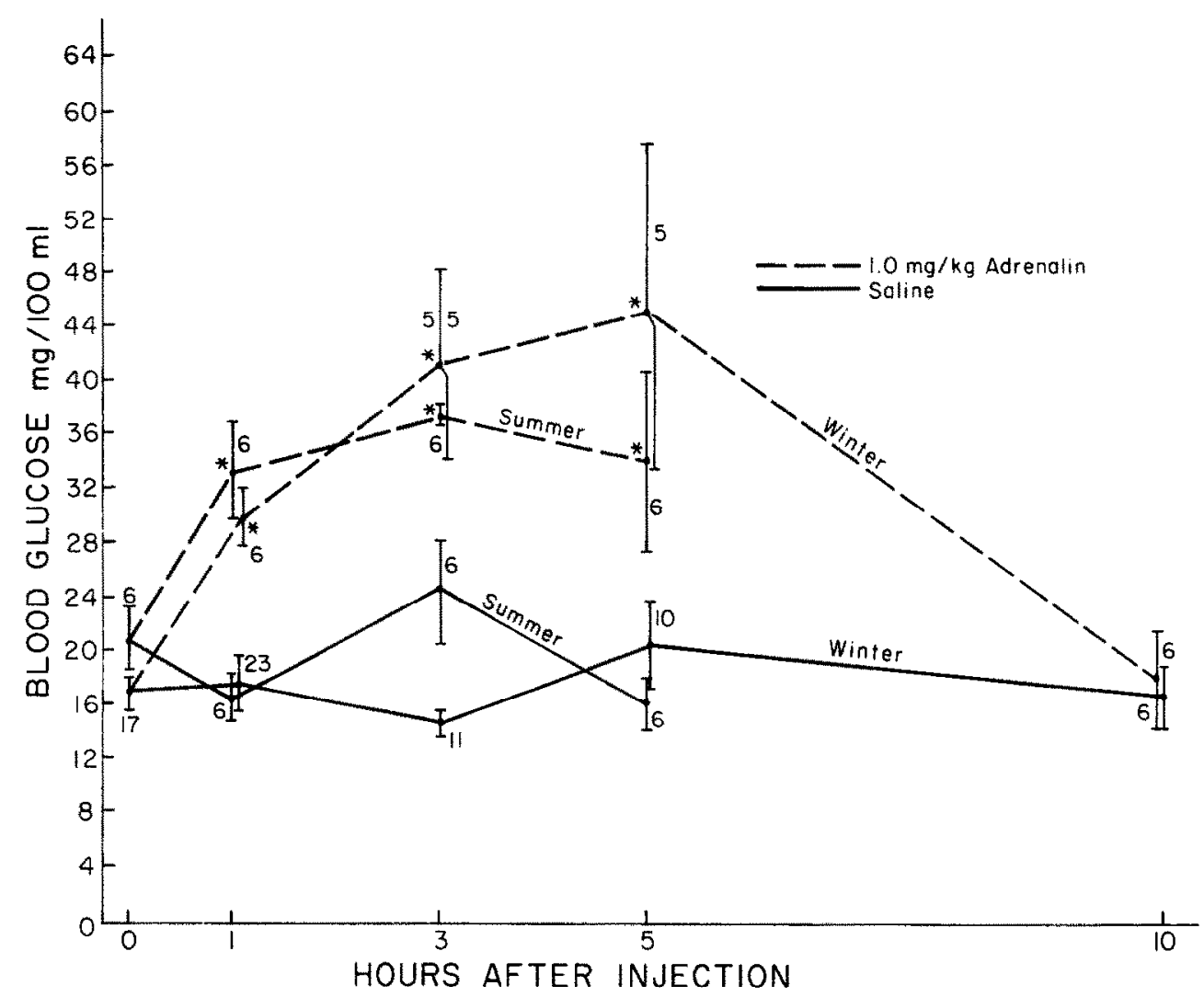

Fig. 2. Effects of adrenalin on frog blood glucose in summer and winter. See legend of Fig. 1.

and lactacidemia far exceeded responses to identical doses at other times of the year. The peak blood glucose level in the fall adrenalin-treated animals $(58.7 \mathrm{mg} \%$ ) was $60 \%$ higher than the peak response in summer or winter animals ( $37 \mathrm{mg} \%$ ), the peak value was reached later in fall frogs, and the hyperglycemia persisted longer in the fall than in the other seasons (Fig. 3). Lactate responses were even more exaggerated than the blood glucose responses (Fig. 4). The peak lactate level $(70 \mathrm{mg} \%$ ) was $100 \%$ greater than the peak at other seasons. The lactacidemia persisted longer in the fall animals, being elevated at $5 \mathrm{hr}$, whereas lactate levels in summer animals had returned to normal by $5 \mathrm{hr}$.

\section{DISCUSSION}

Leopard frogs appear to be changing metabolically throughout the year. The na- ture of these changes has not been studied in detail. It is thought that summer is a period of greater activity, higher metabolic rates (Fromm and Johnson, 1955), greater food intake, and peak growth rates as compared with winter hibernating periods when these processes are minimal. During summer, in spite of the food intake, carbohydrate reserves are low; the reverse is true of winter animals. The transitional seasons, spring and fall, have been studied very little and consequently the metabolic changes are even less well understood. Spring is associated with spawning activity accompanied by falling glycogen levels and a peak in blood glucose level. Whether this peak is a direct consequence of glycogenolytic hormonal regulation or is an indirect effect of various reproductive hormones and/or metabolic hormones such as thyroxine and increased breeding activity is not known. 


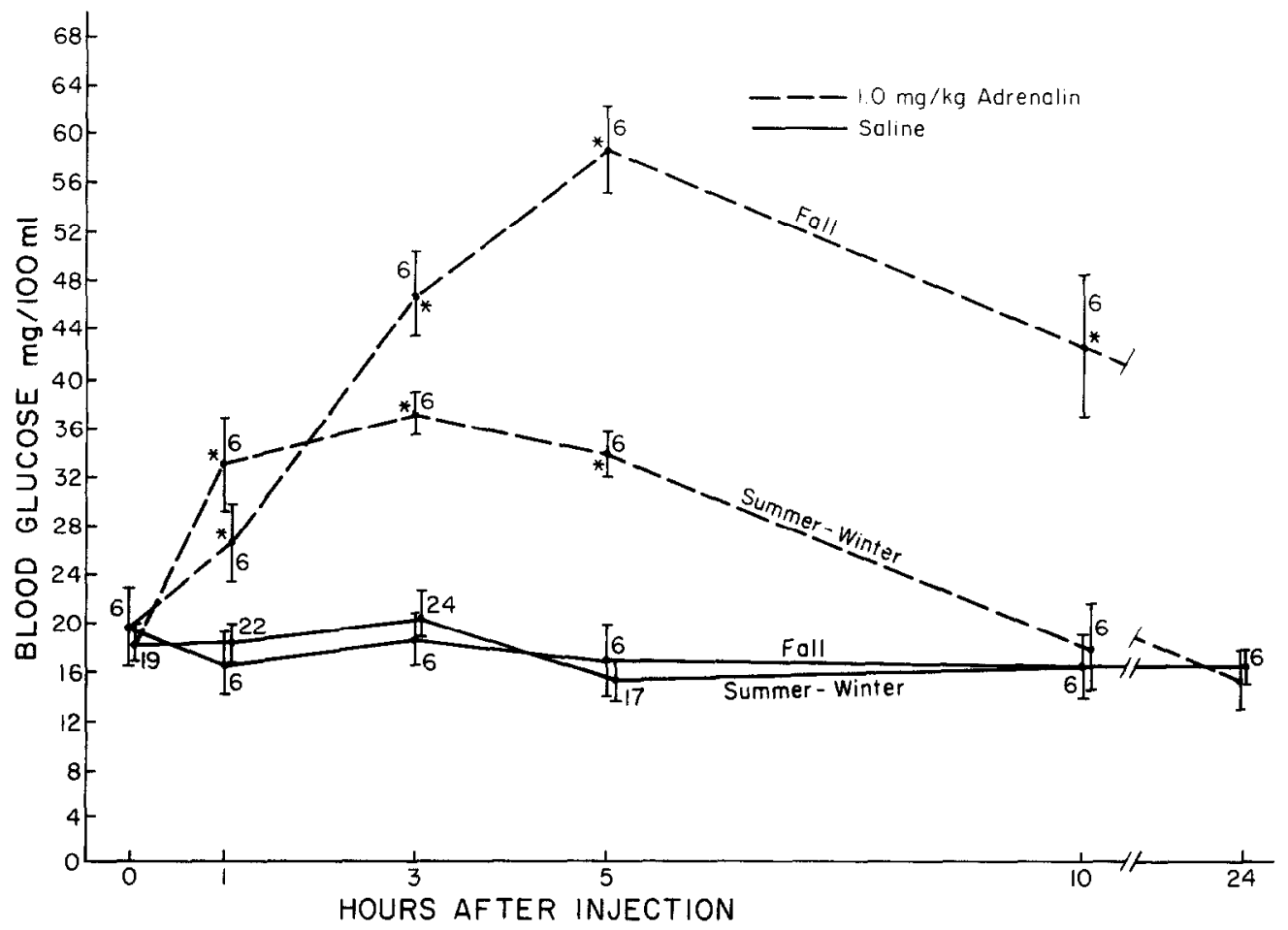

FIG. 3. Effects of adrenalin on frog blood glucose in fall as compared to summer or winter. See legend of Fig. 1.

Fall is a transitional period between summer and winter when physiological adjustments must be made in preparation for winter. Although food sources are waning, Rana pipiens must migrate to the hibernating ponds, acclimate to colder environmental temperatures, and replenish glycogen stores. It is during this season when blood glucose levels are normally as high as during summer, even in frogs adjusted to standard laboratory conditions, that adrenalin exerts its greatest effects. Glucagon, a potentially similar acting glycogenolytic hormone in mammals, does not exhibit this heightened effect in frogs collected in fall but maintained in the laboratory. This suggests a special role for adrenalin in fall or in the adjustments necessary for preparation for winter. The hormone could mobilize extra glucose necessary for fall migratory activity, but until more is known about migration and its energy requirements the merits of this suggestion can not be judged. Adrenalin is thought to be involved in temperature acclimation (Harri and Hedenstam, 1972), but, again, so little is known about this process that the role of adrenalin is only speculative.

The mechanisms by which adrenalin can be most effective during fall include the following: (1) Its secretion rate could be higher; (2) its rate of inactivation could be lower; (3) its target organ(s), liver and muscle, could be more sensitive; (4) due to changes in circulation, more adrenalin might be absorbed and reach the target organs; and (5) glycogen could be limiting at seasons other than fall. On the basis of current knowledge only the last possibility can be negated. Glycogen concentrations are just as high during winter as they are in fall, and yet adrenalin is more effective in fall. Moreover, if increased glycogen concentra- 


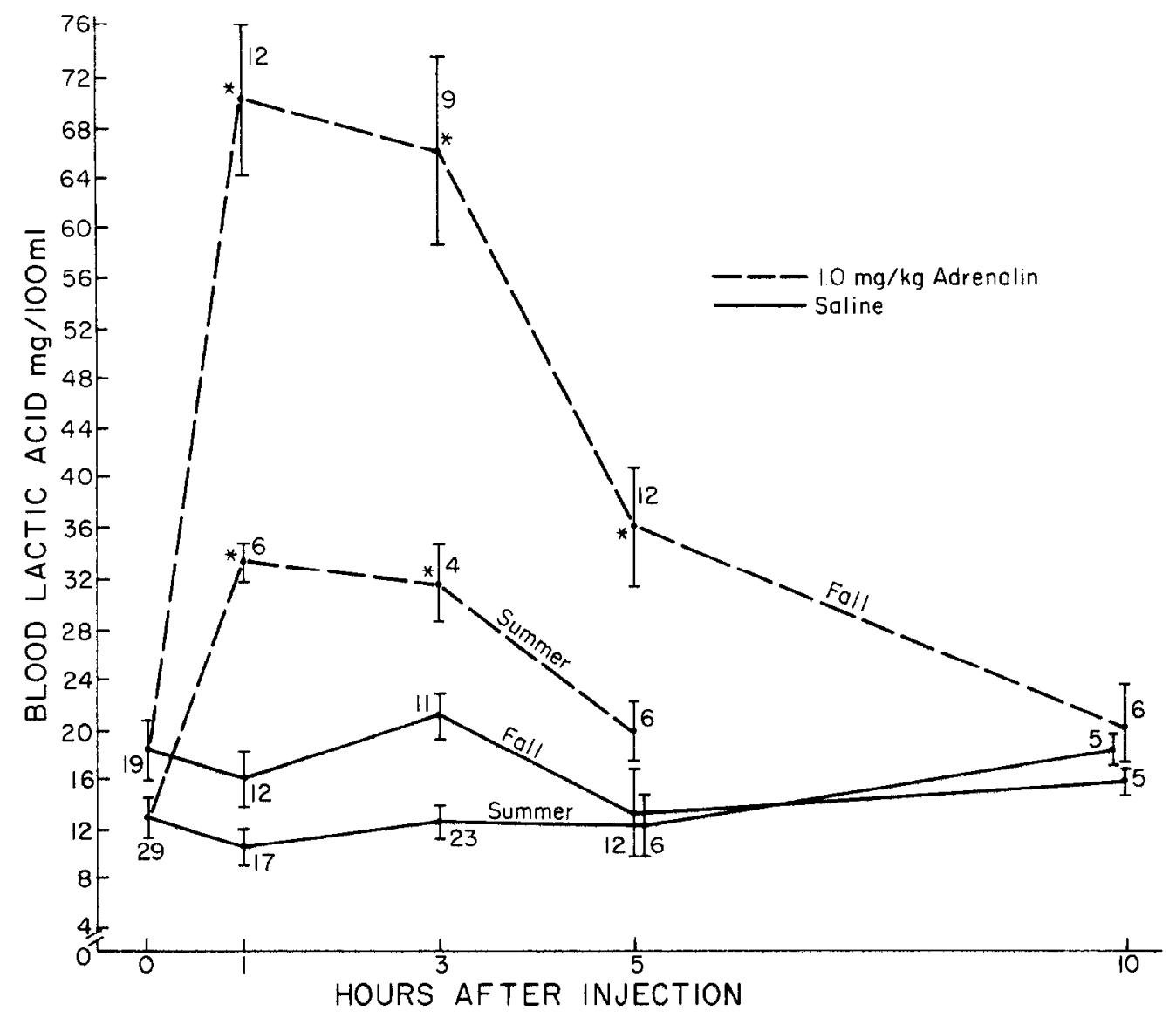

FIG. 4. Effects of adrenalin on frog blood lactic acid in fall as compared to summer or winter. See legend of Fig. 1.

tion per se were the only cause of the increased adrenalin effects, glucagon effectiveness in fall should also have been enhanced. Harri (1972) found that the adrenalin content of the adrenal gland in Rana temporaria was highest in fall and winter and that adrenalin utilization was most intense in warm acclimated frogs placed in the cold. Although this implies nothing about adrenalin secretion rates or tissue sensitivity to the hormone, it does add to the evidence for a role of adrenalin in frogs making the transition from summer to winter physiological conditions.

While it is tempting to assume a seasonal physiological role for adrenalin in frogs living in nature, it must be emphasized that these experiments were conducted on ani- mals adjusted to laboratory conditions. It is possible to rule out nonspecific, but seasonal, effects of handling combined with exogenous hormone administration because seasonal glucagon hyperglycemia was not observed. However, it is not possible to completely rule out a specific seasonal potentiation of adrenalin effects caused by some aspect of handling and rearing procedures. Whether or not adrenalin has an important role in the frog's natural preparation for winter is a problem that needs further study.

\section{ACKNOWLEDGMENTS}

We are grateful to Dan Rittschof for his assistance in collecting frogs. 


\section{REFERENCES}

Byrne, J. J., and White, R. J. (1975). Cyclic changes in liver and muscle glycogen, tissue lipid, and blood glucose in a naturally occurring population of Rana catesbeiana. Comp. Biochem. Physiol. 50A, 709-715.

Ellis, S. (1956). Metabolic effects of epinephrine and related amines. Pharmacol. Rev. 8, 485-562.

Farrar, E. (1972). Some aspects of carbohydrate metabolism and its regulation by adrenalin and glucagon in Rana pipiens. Ph.D. Dissertation, University of Michigan, Ann Arbor, Michigan.

Foá, P. P. (1968). Glucagon. Ergeb. Physiol. 60, 141219.

Fromm, P. O., and Johnson, R. E. (1955). The respiratory metabolism of frogs as related to season. $J$. Cell. Comp. Physiol. 45, 343-359.

Gourley, D. R. H., Suh, T.K., and Brunton, L. I.. (1969). Seasonal differences and the effect of insulin on pyruvate uptake, oxidation and synthesis to glycogen by frog skeletal muscle. Comp. Biochem. Physiol. 29, 509-524.

Hanke, W., and Neumann, V. (1972). Carbohydrate metabolism in amphibia. Gen. Comp. Endocrinol. Suppl. 3, 198-208.
Harri, M. (1972). Effect of season and temperature acclimation on the tissue catecholamine level and utilization in the frog, Rana temporaria. Comp. Gen. Pharmacol. 3, 101-112.

Harri, M., and Hedenstam, R. (1972). Calorigenic effect of adrenaline and noradrenaline in the frog, Rana temporaria. Comp. Biochem. Physiol. 41A, 409-419.

Harri, M. N. E., and Lindgren, D. (1972). Adrenergic control of carbohydrate metabolism in the frog, Rana temporaria. Comp. Gen. Pharmacol. 3, 226-234.

Hermansen, B., and Jörgensen, C. B. (1969). Blood glucose in male toads (Bufo bufo): Annual variation and hormonal regulation. Gen. Comp. Endocrinol. 12, 313-321.

Mizell, S. (1965). Seasonal changes in energy reserves in the common frog, Rana pipiens. Gen. Comp. Physiol. 66, 251-258.

Scholz, R., Schmitz, H., Bücher, Th., and Lampen, J. O. (1959). Über die Wirkung von Nystatin auf Bäckerhefe. Biochem. Z. 331, 71-82.

Smith, C. L. (1954). The relation between seasonal hyperglycaemia and thyroid activity in the frog (Rana temporaria). J. Endocrinol. 10, 184-191. 